\title{
PENGARUH MEDIA PUZZLE BOLA TERHADAP KEMAMPUAN MENGENAL WARNA PADA SISWA TUNAGRAHITA SEDANG KELAS III DI SDLB BHAKTI LUHUR JEMBER
}

\author{
Agustina Ase \\ PLB IKIP PGRI JEMBER \\ Email: Agustinaase123@gmail.com
}

\begin{abstract}
Abstrak
Penelitian ini menggunakan kuantitatif metode eksperimen Single Subject Research (SSR), dapat dilakukan sebanyak 2 minggu yaitu tahap baseline 1 minggu dan intervensi 1 minggu. Subyek penelitian adalah siswa tunagrahita sedang kelas III yang berinisial KA. Pada fase baseline hasil penelitian menunjukkan KA mendapatkan skor persentasenya 41\%, 41\%, 50\%, 50\% dan 41\% dan setelah memasuki minggu kedua siswa diberikan intervensi oleh peneliti sehingga skor yang diperoleh siswa meningkat yaitu 69\%, 75\%, 75\%, 72\% dan 77\%. Dari hasil penelitian ini dikatakan bahwa media puzzle bola berpengaruh terhadap kemampuan mengenal warna pada siswa tunagrahita sedang kelas III di SDLB Bhakti Luhur Jember.

Kata kunci: Tunagrahita sedang, Media puzzle bola, Kemampuan mengenal warna
\end{abstract}

\section{PENDAHULUAN}

Anak tunagrahita adalah kemampuana anak dibawah rata-rata dengan keterbatasan pada intelegensi dan komunikasinya. kemampuan yang dimiliki dapat digolongkan sebagai berikut: tunagrahita ringan, sedang dan berat.

Menurut Skala Binet dan Skala Weschler (dalam Atmaja, 2018, hlm. 101) tunagrahita sedang IQ 51-36 pada Skala Binet dan 54-40 pada Skala Weschler. Sedangkan menurut Kosasih (2012:143) secara akademik seperti belajar menulis, membaca dan berhitung bagi anak tunagrahita sedang sangat sulit, anak hannya bisa mampu menulis namanya sendiri, dan melaksanakan kegiatan rumah tangga.
Jadi dapat disimpulkan bahwa untuk mengembangkan kemampuan pada anak tunagrahita sedang membutuhkan pelayanan sesuai dengan kemampuan anak karena keterlambatan kecerdasan.

Hambatan kesulitan dalam pembelajaran anak tunagrahita adalah seperti mengenal warna. Kemampuan mengenal warna sangat penting bagi perkembangan kognitif anak sebab warna dapat merangsang penglihatan anak. Warna merupakan unsur keindahan dan seni dalam kehidupan yang terlihat oleh mata.

Pada Kurikulum (2006, hlm. 149) warna merupakan materi mata pelajaran seni dan budaya. Warna dapat dibagi menjadi 4 macam menurut teori dari Brewster 1831 (dalam Nugroho, 2008) yaitu warna primer, sekunder, 
tersier dan netral. Dari keempat warna tersebut warna yang pertama kali dipelajari anak tunagrahita sedang adalah warna dasar karena keterbatasan intelegensi yang dimiliki oleh anak tunagrahita mengalami kesulitan dalam mengingat ataupun menerima materi pembelajaran.

Dari observasi yang telah dilakukan di SDLB Bhakti Luhur Jember, terdapat salah satu anak tunagrahita sedang yang belum memahami tiga warna dasar, anak hanya mengetahui dan hafal macam warna tanpa bisa membedakan. Selama ini anak belajar mengenal warna menggunakan media dari kertas origami.

Salah satu media yang dapat mendukung terciptanya rangsangan pada anak dalam mengenal warna dasar adalah media puzzle bola. Media merupakan salah satu alat bantu sebagai perantara kepada siswa dalam kegiatan pembelajaran. Sedangkan puzzle merupakan media yang dapat dimainkan dengan cara bongkar pasang yang akan membentuk gambar, ataupun huruf.

Tujuan dari media puzzle bola adalah untuk mengembangkan kecerdasan anak dalam aspek visual, intra personal, melatih kemampuan motorik, serta pemahaman anak dalam mengenal warna. Puzzle juga memiliki kelebihan seperti menarik minat dan perhatian siswa, bersifat konkrit dan mengatasi keterbatasan ruang dan waktu. Berdasarkan permasalahan diatas peneliti tertarik untuk melakukan penelitian tentang "Pengaruh Media Puzzle Bola terhadap kemampuan mengenal warna pada siswa tungrahita sedang kelas III di SDLB Bhakti Luhur Jember"

\section{METODE}

Penelitian ini dilakukan di SDLB Bhakti Luhur Jember. Subjek penelitian adalah salah satu siswa tunagrahita sedang kelas III SD yang berinisial KA. KA belum mampu mengenal warna, hanya mengenal dan mengetahui warna tanpa membedakan sehingga pemahaman tentang warna masih sangat kurang oleh karena itu peneliti akan mengenalkan warna yang hanya terbatas pada warna merah, kuning dan biru. Waktu penelitian dilakukan 2 tahapan yaitu tahapan baseline dan tahapan intervensi. Pada tahapan baseline dilakukan sebanyak 5 kali sesi pengamatan dengan waktu 1 jam. Sedangkan pada tahapan intervensi dilakukan sebanyak 5 kali sesi dengan waktu 1 jam.

Instrumen yang digunakan saat penelitian menggunakan parameter persentase. Menurut Sunanto, (2005, hlm. 16) alat yang digunakan oleh peneliti dalam mengukur perilaku dalam bidang akademik maupun sosial di sebut persen. Dihitung dengan cara jumlah suatu perilaku yang terjadi kemudian dikalikan 100\%.

Tes yang diberikan adalah tes perbuatan. Selanjutnya data dianalisis 
dalam kondisi dan antar kondisi. Analisis alam kondisi merupakan menganalisis perubahan data dalam satu kondisi misalnya kondisi baseline atau kondisi intervensi menurut Sunanto (2005, hlm. 96).

\section{HASIL DAN PEMBAHASAN}

Penelitian fase baseline kemampuan anak dalam mengenal warna dengan persentase $41 \%, 41 \%$, 50\%, 50\% dan 41\%. Ketika intervensi mulai diberikan menggunakan media puzzle bola siswa mengalami peningkatan hal ini dikarenakan media puzzle bola yang digunakan dalam penelitian menarik, KA juga selalu antusias dalam mengikuti pembelajaran mengenal warna dengan persentase yang diperoleh siswa pada fase intervensi diantaranya 69\%, 75\%, $75 \%$, $72 \%$ dan $77 \%$.

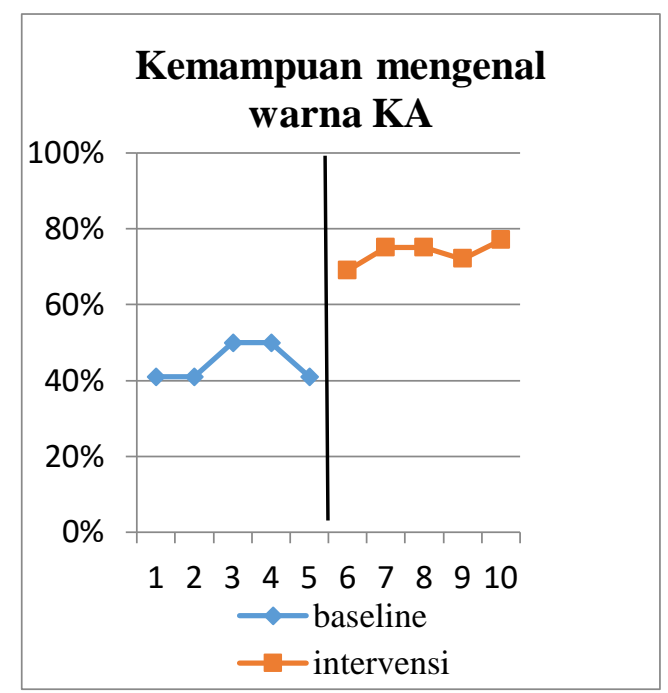

Berdasarkan grafik diatas maka kemampuan anak di fase baseline mencapai 50\%, setelah diberikan intervensi kemampuan anak dalam mengenal warna semakin meningkat dengan persentase tertinggi $77 \%$ hal dibuktikan bahwa anak mampu mengenal warna sesuai dengan instrument yang ditentukan namun hanya ada satu warna perlu bantuan verbal siswa

Tabel 1. Analisis dalam kondisi.

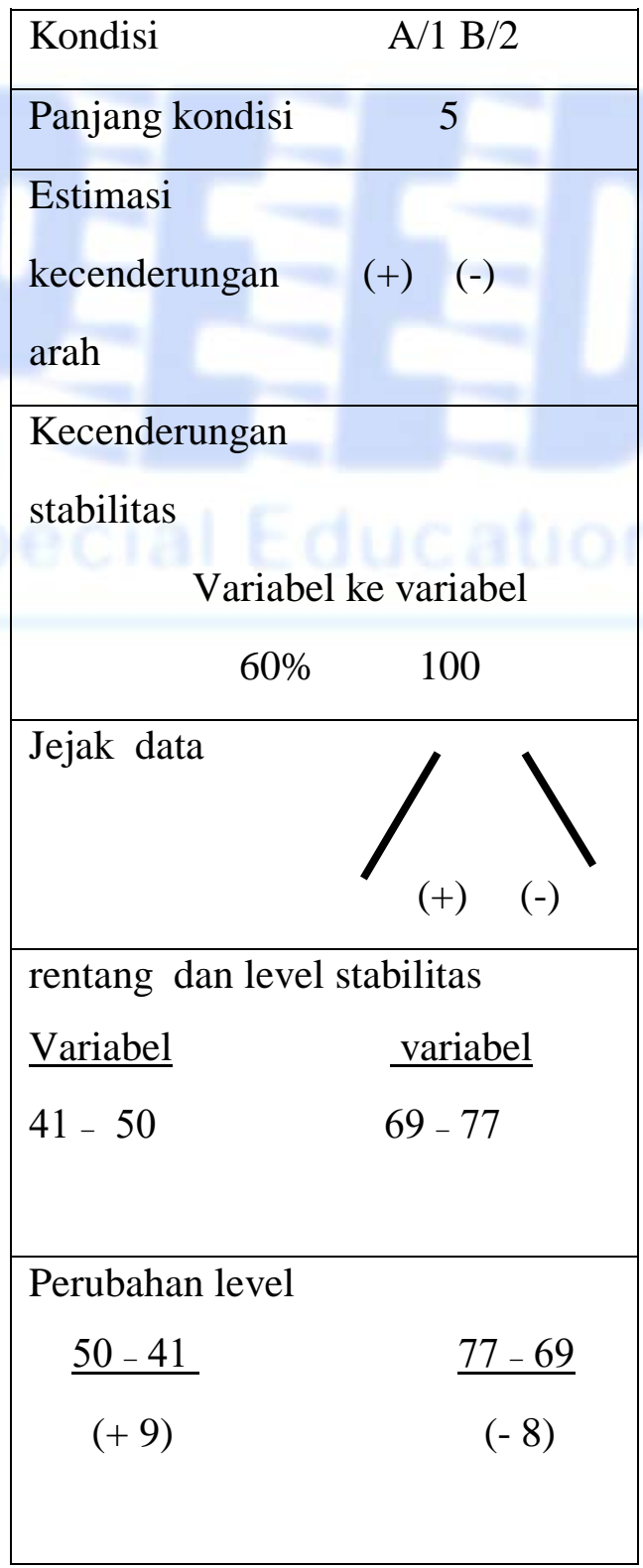


Tabel 2. Rangkuman hasil analisis antar kondisi

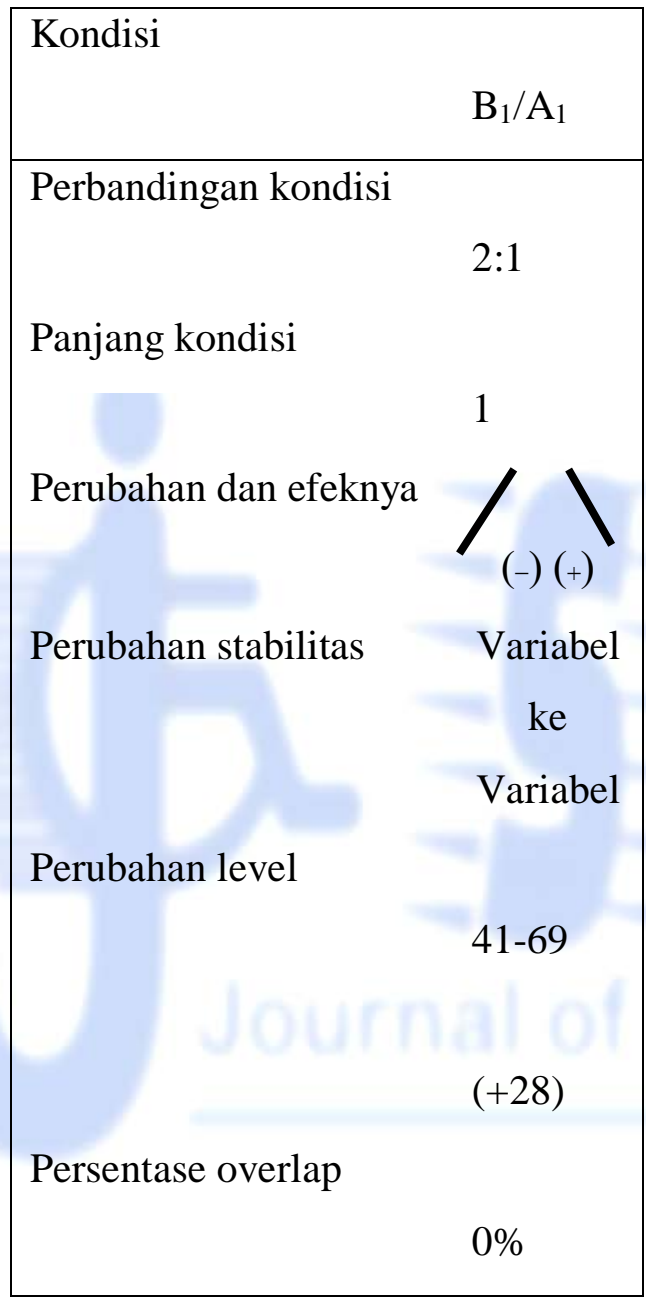

\section{PENUTUP}

\section{Simpulan}

Berdasarkan hasil perolehan data dalam bentuk analisis antar kondisi dan analisis visual dalam kondisi dapat disimpulkan anak tunagrahita sedang mengalami peningkatan dalam pengenalan warna menggunakan media puzzle bola. Penelitian fase baseline (A) hasil pemerolehan nilai KA adalah $15,15,18,18,15$ dengan persentasenya adalah 41\%, 41\%, 50\%, 50\% dan41\%. Pelaksanaan fase baseline (A) menurun karena siswa belum diberikan perlakuan, siswa masih beradaptasi dengan peneliti dan siswa juga kurang konsentrasi dalam belajar dikarenakan siswa diganggu oleh teman-temannya ketika sedang belajar. Walaupun siswa diganggu oleh teman-temannya, siswa masih mampu menjawab dengan batuan verbal ataupun non verbal.

Setelah siswa diberikan perlakuan atau intervensi siswa mengalami peningkatan karena media puzzle bola yang digunakan menarik, siswa juga memiliki minat belajar dalam mengenal warna sehingga memperoleh skor 25, 27, 27, 26 dan 28 dan persentasenya adalah 69\%, 75\%, 75\%, $72 \%$ dan $77 \%$. Pada fase intervensi ini KA sudah mampu menyebut warna merah, biru dengan bantuan verbal, sedangkan untuk menunjuk dan memasukkan KA dapat menyelesaikan tanpa bantuan atau mandiri. Dari fase baseline sampai fase intervensi KA belum mampu menyebut warna kuning, KA selalu menyebut kuning menjadi putih.

\section{Saran}

Adapun beberapa saran sebagai berikut:

(1) Sekolah, menyediakan sarana dan prasarana yang sesuai dengan kebutuhan anak. (2) Guru 
memodifikasi media puzzle bola menjadi warna sekunder atau pun warna tersier dalam mengenal warna

(3) Peneliti selanjutnya diharapkan untuk mengenalkan warna sekunder dan tersier dengan memodifikasi media puzzle bola.

\section{DAFTAR PUSTAKA}

Atmaja, R. (2018). Pendidikan dan Bimbingan Anak Berkebutuhan Khusus. Bandung: PT. Remaja Rosdakarya

Kurikulum. (2006). Seni Budaya Dan Keterampilan.

Kosasih, E (2012). Cara Bijak Memahami Anak Berkesulitan Belajar. Bandung:Yrama Widya

Nugroho, Eko. (2008). Pengenalan Teori Warna. Bandung: Andi Publisher

Sunanto, Juang. (2005). Pengantar Penelitian dengan Subyek Tunggal. Bandung: UPI 